\title{
Early virological response may predict treatment response in sofosbuvir-based combination therapy of chronic hepatitis $c$ in a multi-center "real-life" cohort
}

Niels Steinebrunner ${ }^{1}$, Martin F. Sprinzl| $\left.\right|^{2}$ Tim Zimmermann², Marcus A. Wörns², Thomas Zimmerer ${ }^{3}$, Peter R. Galle², Wolfgang Stremmel ${ }^{1}$, Christoph Eisenbach ${ }^{1}$, Kerstin Stein ${ }^{4}$, Christoph Antoni ${ }^{3}$, Jörn M. Schattenberg ${ }^{2+}$ and Anita Pathil ${ }^{1 *}$

\begin{abstract}
Background: The combination of sofosbuvir (SOF), ribavirin (RBV) and peg-interferon-alfa-2a (peg-IFN-alfa-2a) as well as the combination of SOF and RBV for the treatment of patients infected with hepatitis $\mathrm{c}$ virus (HCV) has improved rates of sustained virological response (SVR) considerably in recent trials. However, there is only limited data concerning the efficacy and safety in a "real-life" cohort.

Methods: We analyzed a cohort of 119 patients with chronic HCV infection treated at four investigational sites in Germany. All patients received either a combination treatment of SOF, RBV and peg-IFN-alfa-2a or SOF and RBV.

Results: The rates of SVR at 12 weeks after end of treatment (SVR 12) were as follows: Among 76 patients with genotype 1 infection the SVR 12 rate was $74 \%(n=56)$, among 14 patients with genotype 2 infection the SVR 12 rate was $79 \%(n=11)$, among 24 patients with genotype 3 infection the SVR 12 rate was $92 \%(n=22)$ and among 5 patients with genotype 4 infection the SVR 12 rate was $80 \%(n=4)$. Of all 26 patients with a relapse in our cohort, $69 \%(n=18)$ of these patients presented with liver cirrhosis and $58 \%(n=15)$ were treatment experienced. Notably, the level of HCV-RNA after 4 weeks of treatment was a significant predictor of treatment response in genotype 1 patients. Patients with HCV-RNA levels $\geq 12 \mathrm{IU}$ ml-1 after 4 weeks of treatment achieved SVR 12 only in $30 \%(n=17 / 56, p<0.0001)$ of cases and treatment response was even lower with SVR 12 of $25 \%(n=5 / 20$, $p=0.0016)$ in the subgroup of patients with cirrhosis.
\end{abstract}

Conclusion: We observed a high rate of SVR 12 with SOF-based treatment regimes, however probably due to the high number of patients with liver cirrhosis and prior treatment experience, treatment response rates were lower than in previously published trials. In genotype 1 patients the analysis of early virological response may predict treatment response in SOF-based combination therapies.

\footnotetext{
* Correspondence: anita.pathil-warth@med.uni-heidelberg.de

${ }^{\dagger}$ Equal contributors

'Department of Internal Medicine IV, University Hospital Heidelberg,

Heidelberg, Germany

Full list of author information is available at the end of the article
}

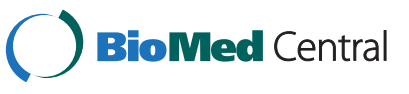

(c) 2015 Steinebrunner et al. Open Access This article is distributed under the terms of the Creative Commons Attribution 4.0 International License (http://creativecommons.org/licenses/by/4.0/), which permits unrestricted use, distribution, and reproduction in any medium, provided you give appropriate credit to the original author(s) and the source, provide a link to the Creative Commons license, and indicate if changes were made. The Creative Commons Public Domain Dedication waiver (http://creativecommons.org/publicdomain/zero/1.0/) applies to the data made available in this article, unless otherwise stated. 


\section{Background}

Chronic hepatitis C virus (HCV) infection affects an estimated 170 million people worldwide with a prevalence of approximately $0.2-2 \%$ in the United States and Europe $[1,2]$. As HCV patients are at risk for developing end-stage liver disease with a variety of complications including hepatocellular carcinoma and decompensated liver cirrhosis with the need for liver transplantation, chronic HCV infection is associated with an elevated risk for liver-related mortality [3-5].

The next generation direct acting antiviral (DAA) sofosbuvir (SOF), which has been recently approved by national health authorities, represents the next milestone in the development of new therapeutic options and opens up potent treatment regimes for chronic HCV patients. SOF is an oral nucleotide analogue inhibitor of the HCV-specific NS5B polymerase with high antiviral efficacy and a favorable safety profile [6-8]. The efficacy of SOF-based treatment regimes has been demonstrated in different phase II and phase III trials $[9,10]$.

However, due to preselected patient populations and underrepresentation of difficult-to-treat patients, such as treatment experienced cirrhotics, these data may differ in a real-life setting and the validation of these results in a diverse patient population with less favorable conditions towards an SVR regarding concomitant diseases or constitutional factors may yield additional aspects and knowledge valuable for the future management of affected patients [11, 12].

Thus, we aimed to investigate the efficacy and safety of the SOF-based treatment regimes SOF, RBV and pegIFN-alfa-2a or SOF and RBV alone in our "real-life" cohort from four tertiary referral centres in Germany.

\section{Patients and methods}

\section{Patient population and study design}

We analyzed clinical and laboratory data of all consecutive patients aged 18 years or older with treatment initiation for chronic HCV genotype 1, 2, 3 or 4 infection between January and June 2014 in a retrospective, longitudinal study at four investigational sites in Germany. One patient was non-adherent to the antiviral treatment plan and showed no SVR. This patient was included in the intention-to-treat (ITT) analysis.

Patients were treated with a combination treatment of SOF, RBV and peg-IFN-alfa-2a or SOF and RBV for either 12 or 24 weeks, depending on genotype, pretreatment history, presence of liver cirrhosis or contraindications according to the approved treatment recommendations [13]. SOF was administered at $400 \mathrm{mg}$ once daily and RBV dose was based on body weight (1000 mg per day for $<75 \mathrm{~kg}$ and $1200 \mathrm{mg}$ per day for $\geq 75 \mathrm{~kg}$ in a divided dose) in all patients. Peg-IFN-alfa-2a was applied at a dosing of $180 \mu \mathrm{g}$ once weekly to patients with genotype 1,3 or 4 according to the individual treatment protocol. Serum HCV-RNA and standard laboratory tests were regularly assessed at baseline, at weeks 4, 12 and 24 of treatment and at additional time points, if deemed necessary, as well as at 12 weeks of follow-up. The lower limit of quantification (LLOQ) was $12 \mathrm{IU} / \mathrm{ml}$ (Abbott RealTime (ART) HCV assay (Abbott Molecular, Des Plaines, IL, USA). Liver cirrhosis was confirmed by liver histology or by evaluation of data sets from non-invasive tests, comprising fibroscan measurement, ultrasound examination, imaging by computed tomography or magnetic resonance, presence of esophageal varices and laboratory values. No patient with decompensated liver cirrhosis was included in the analysis. The institutional Ethics Committee (Ethikkommission der Medizinischen Fakultät Heidelberg) approved the protocol and the study was conducted in accordance with the Guidelines for Good Clinical Practice and the Declaration of Helsinki.

\section{Statistical analysis}

Continuous data are expressed by mean values and standard deviation. Categorical variables are expressed as absolute and relative numbers. Continuous data over time was analyzed with one-sample $t$-test and categorical data with chi-square test. A p value $<0.05$ was considered statistically significant. Statistical analysis was performed using GraphPad Prism software (version 6.0, GraphPad Software, Inc., La Jolla, CA, USA).

\section{Results}

\section{Characterization of the study population}

We enrolled 119 patients with chronic HCV infection at four investigational sites in Germany. HCV genotype 1 was present in $64 \%(n=76)$ of patients, followed by genotype 3 in $20 \%(n=24)$, genotype 2 in $12 \%(n=14)$ and genotype 4 in $4 \%(n=5)$ of patients. The study population consisted of a large proportion of patients with liver cirrhosis $46 \%(n=55)$. Of all patients, $50 \%$ $(n=60)$ were treatment experienced and $23 \%(n=27)$ had received a protease inhibitor in a previous therapy. The patient population comprised patients co-infected with human immunodeficiency virus (HIV) $(n=9)$ as well as patients after liver transplantation $(n=14)$. The distribution of patients after liver transplantation among genotypes was 7 patients with genotype 1 and 7 patients with genotype 3 . Baseline characteristics of the study cohort are shown in Table 1. A combination treatment of SOF, RBV and peg-IFN-alfa-2a was administered to $68 \%$ $(n=81)$ of patients and $32 \%(n=38)$ of patients were treated with SOF and RBV for 12 to 24 weeks. In detail, patients with genotype 1 received either a therapy regime of SOF + peg-IFN-alfa-2a + RBV over 12 weeks $(43 \%(n=51))$ or 24 weeks $(10 \%(n=12))$ or a therapy regime of SOF $+\mathrm{RBV}$ over 24 weeks $(11 \%(n=13))$. 
Table 1 Baseline characteristics of the study population

\begin{tabular}{ll}
\hline Demographics & $50 \pm 12(20-77)$ \\
Mean age (years) & $74 \%(88)$ \\
Male sex & \\
HCV genotype & $20 \%(23)$ \\
1a & $44 \%(53)$ \\
1 b & $12 \%(14)$ \\
2 & $20 \%(24)$ \\
3 & $4 \%(5)$ \\
4 & $3.23 \pm 6.61(0.02-34.50)$ \\
Mean HCV-RNA (10E6 IU ml-1) & $46 \%(55)$ \\
Cirrhosis & \\
Treatment history & $50 \%(59)$ \\
Treatment naive & $50 \%(60)$ \\
Treatment experienced & $23 \%(27)$ \\
Protease inhibitor experienced & \\
Clinical chemistry & $155 \pm 74(13-396)$ \\
Platelets (10E3 $\mu$ l- 1 ) & $1.0 \pm 0.8(0.2-4.7)$ \\
Total bilirubin (mg dl-1) & $1.09 \pm 0.25(0.84-2.65)$ \\
INR & $0.78 \pm 0.21(0.43-1.85)$ \\
Creatinine (mg dl- 1$)$ &
\end{tabular}

Patients with genotype 2 were exclusively treated with a 12 -week regimen of SOF and RBV $(12 \%(n=14))$. A therapy regime of $\mathrm{SOF}+$ peg-IFN-alfa- $2 \mathrm{a}+\mathrm{RBV}$ over 12 weeks was applied in $12 \%(n=14)$ and of SOF + RBV over 24 weeks in $8 \%(n=10)$ of patients with genotype 3 . In patients with genotype 4 the therapy regimes and treatment duration was SOF + peg-IFN-alfa-2a + RBV over 12 weeks in $3 \%(n=4)$ and SOF + RBV over 24 weeks in $1 \%(n=1)$ of cases (Table 2$)$.

\section{Efficacy of sofosbuvir-based therapies}

The SVR 12 rates according to the HCV genotype were as follows: Among 76 patients with genotype 1 infection the SVR 12 rate was $74 \%(n=56), 14$ patients with genotype 2 infection had a SVR 12 rate of $79 \%(n=11)$, among 24 patients with genotype 3 infection the SVR 12

Table 2 Therapy regime and treatment duration

\begin{tabular}{lllll}
\hline & GT 1 & GT 2 & GT 3 & GT 4 \\
\hline SOF + PEG + RBV & & & & \\
12 weeks & $43 \%(51)$ & 0 & $12 \%(14)$ & $3 \%(4)$ \\
24 weeks & $10 \%(12)$ & 0 & 0 & 0 \\
SOF + RBV & & & & \\
12 weeks & 0 & $12 \%(14)$ & 0 & 0 \\
24 weeks & $11 \%(13)$ & 0 & $8 \%(10)$ & $1 \%(1)$ \\
\hline
\end{tabular}

Data are expressed as percent (number)

GT genotype, SOF sofosbuvir, PEG pegylated-interferon, $R B V$ ribavirin rate was $92 \%(n=22)$ and 5 patients with genotype 4 infection achieved a SVR 12 rate of $80 \%(n=4)$. Overall, 26 patients experienced a relapse in our cohort, $69 \%(n=18)$ of these patients presented with liver cirrhosis and $58 \%$ $(n=15)$ were treatment experienced. The patient group with cirrhosis and previous treatment experience had the lowest SVR 12 rates in all four genotypes. Out of all 26 patients with a relapse in our cohort, $50 \%(n=13)$ presented with both negative predictors (Fig. 1).

In a subgroup of patients with genotype $1 \mathrm{HCV}$ infection treated with SOF plus RBV and peg-IFN-alfa-2a for 12 weeks SVR 12 rates were $80 \%(n=41 / 51)$ and in those treated for 24 weeks SVR 12 rates were $75 \%$ ( $n=$ $9 / 12$ ). The results in both groups were not statistically different $(p=0.6779)$. However, it has to be considered that 11 out of 12 patients treated over a 24-week period with this regimen had cirrhosis and were treatmentexperienced.

Further analysis indicated that besides the presence of cirrhosis, the level of HCV-RNA by week 4 of treatment was a significant predictor of treatment response in our genotype 1 population (Table 3 ). Patients with $\mathrm{HCV}$ RNA levels $\geq 12$ IU ml-1 after 4 weeks of treatment achieved SVR 12 only in $30 \%$ of cases and treatment response was even lower with SVR 12 of $25 \%$ in the subgroup of genotype 1 patients with cirrhosis (Fig. 2). Interestingly, HCV-RNA levels $\geq 12$ IU ml-1 after 4 weeks of treatment was only associated with treatment failure in patients receiving an IFN-containing regime but not in patients on SOF + RBV (Fig. 3). In patients with HCV genotype 1 infection, there was a significant decline in total bilirubin levels when comparing the time points of treatment initiation and of SVR 12 (Table 4).

\section{Side effects of sofosbuvir-based therapies}

In the treatment regimes consisting of SOF plus RBV and peg-IFN-alfa-2a as well as consisting of SOF plus RBV alone, the most common adverse events were fatigue and myalgia. No severe adverse events were reported. There was a significant difference in the reported side effect of hair loss in the two groups. With respect to hematologic abnormalities, anemia was most frequently observed, an event that is consistent with the well-known side effects of peg-IFN-alfa-2a and RBV. The rates of anemia, reduced white cell count and platelet count differed significantly between the two treatment groups. The SOF plus RBV therapy regime was generally well tolerated with fewer observed side effects as compared to the treatment with SOF plus RBV and peg-IFN-alfa-2a (Table 5).

\section{Discussion}

The approval of SOF, the novel nucleotide analogue NS5B polymerase inhibitor, represents a breakthrough in the treatment of chronic $\mathrm{HCV}$ and has become the 
A

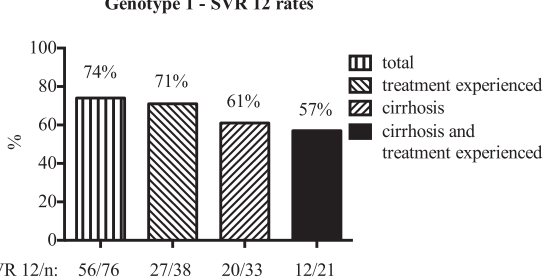

$\begin{array}{lllll}\text { SVR } 12 / \mathrm{n}: & 56 / 76 & 27 / 38 & 20 / 33 & 12 / 21\end{array}$

C

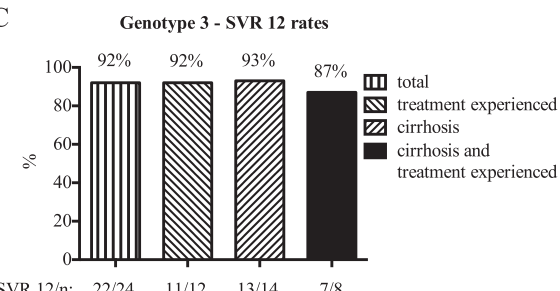

B

Genotype 2 - SVR 12 rates

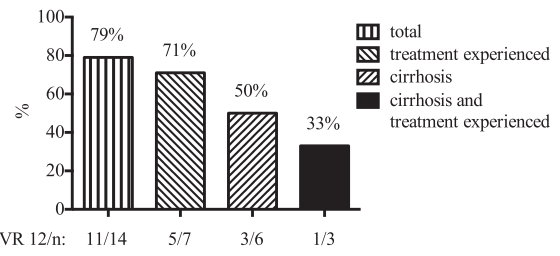

D

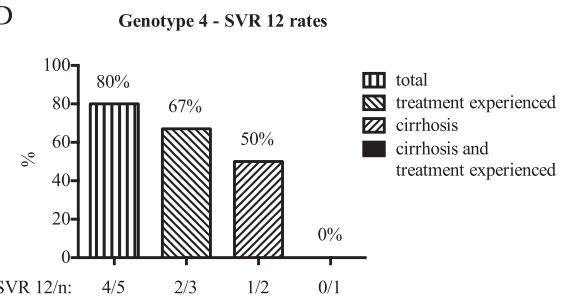

Fig. 1 Efficacy of treatment of the study patients. Sustained virological response rates after 12 weeks after the end of treatment (SVR 12) are shown for patients with HCV genotype 1, 2, 3 or 4 (a-d). Patients were sub-classified for previous treatment experience or presence of cirrhosis. $n=$ total number of patients

backbone of current therapy regimes. SOF-based therapies are the novel standard of care with high antiviral activity, broad genotypic coverage and a high barrier to resistance $[6-8,14,15]$. During therapy with SOF, no virological breakthrough has been reported so far $[14,16]$.

However, many difficult-to-treat patient populations hitherto have been understudied. Thus, we included a high number of patients with cirrhosis in our study, since HCV treatment represents a high priority particularly in this patient group. As HCV recurrence after liver transplantation is universal and bears a high risk of premature graft failure, we also analyzed patients after liver transplantation in our study. Previously, in the abovementioned patient groups, IFN-based HCV therapies were limited because of toxicity and poor efficacy [4]. Additionally, many patients in our study were treatment experienced and several of those had received a protease inhibitor in a previous therapy. The study population further comprised patients co-infected with human immunodeficiency virus (HIV). Recent data has shown that the outcome of DAA-based therapies in $\mathrm{HCV} / \mathrm{HIV}$ coinfected patients is comparable to the $\mathrm{HCV}$ cure rates in

Table 3 Predictors of response for patients with HCV genotype 1 infection

\begin{tabular}{llll}
\hline & SVR 12 & Relapse \\
& total: $74 \%(56)$ & total: $26 \%(20)$ \\
\hline Age $<65$ years & $95 \%(53)$ & $85 \%(17)$ & 0.1698 \\
Age $\geq 65$ years & $5 \%(3)$ & $15 \%(3)$ \\
Female & $34 \%(19)$ & $20 \%(4)$ \\
Male & $66 \%(37)$ & $80 \%(16)$ \\
Non-cirrhotic & $64 \%(36)$ & $35 \%(7)$ \\
Cirrhotic & $36 \%(20)$ & $65 \%(13)$ \\
Treatment naive & $52 \%(29)$ & $45 \%(9)$ \\
Treatment experienced & $48 \%(27)$ & $55 \%(11)$ \\
HCV-RNA $<6(10 \mathrm{E} 6 \mathrm{IU} \mathrm{ml}-1)$ at baseline & $79 \%(44)$ & $85 \%(17)$ \\
HCV-RNA $\geq 6(10 \mathrm{E} 6 \mathrm{IU} \mathrm{ml}-1)$ at baseline & $21 \%(12)$ & $15 \%(3)$ \\
HCV-RNA $<12(\mathrm{IU} \mathrm{ml}-1)$ after 4 weeks of treatment & $70 \%(39)$ & $35 \%(7)$ \\
HCV-RNA $\geq 12(\mathrm{IU} \mathrm{ml}-1)$ after 4 weeks of treatment & $30 \%(17)$ & $65 \%(13)$ \\
Platelets $<100(10 \mathrm{E} 3 \mu \mathrm{l}-1)$ at baseline & $18 \%(10)$ & $30 \%(6)$ \\
Platelets $\geq 100(10 \mathrm{E} 3 \mu \mathrm{l}-1)$ at baseline & $82 \%(46)$ & $70 \%(14)$ \\
\hline
\end{tabular}

Data are expressed as percent (number)

SVR 12 sustained virological response at 12 weeks after end of treatment Boldface data statistically significant 


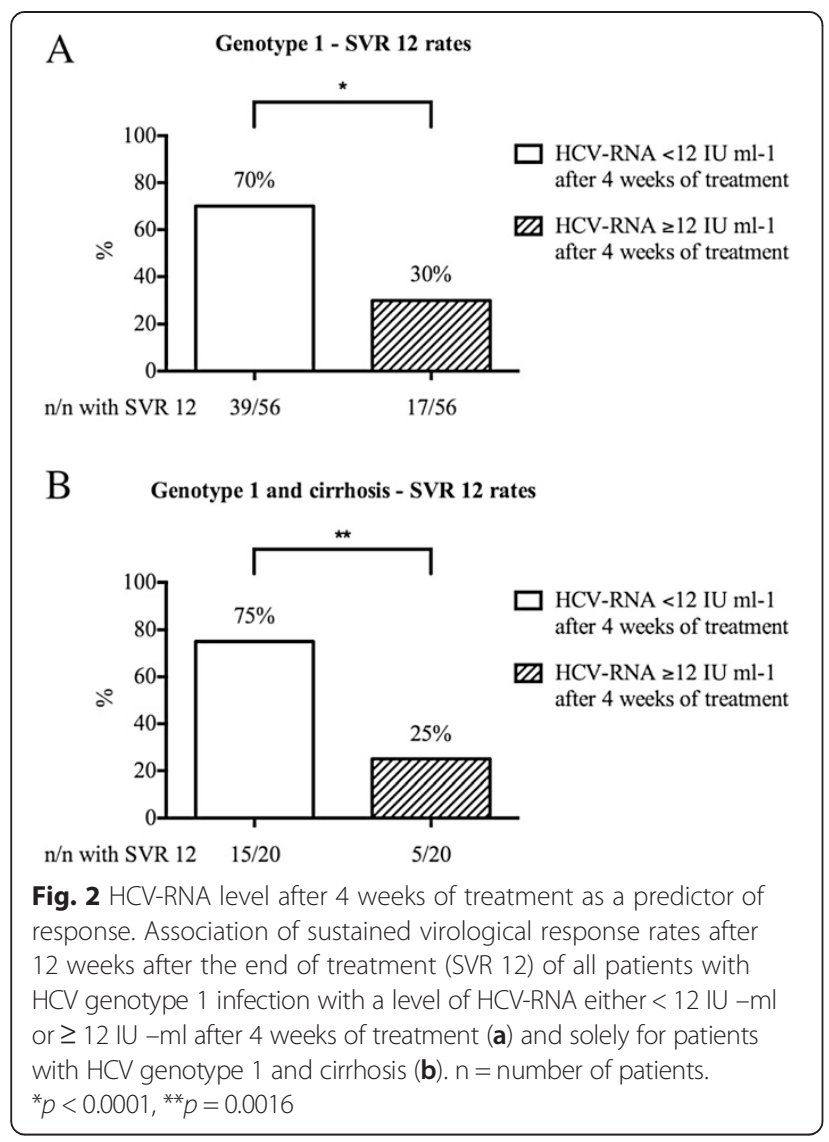

$\mathrm{HCV}$ mono-infected patients and indication and drug choice should follow the general guidelines for $\mathrm{HCV}$ mono-infected subjects [17]. Therefore, HCV/HIV coinfected individuals are no longer regarded as a special patient population by major guidelines [13]. Instead, with current DAA-based therapies, genotype 3 infected patients or special populations, including patients with renal insufficiency or decompensated cirrhosis, have shifted into the focus as difficult-to-treat populations.

Considering overall SVR 12 rates, patients with $\mathrm{HCV}$ genotype 1 infection, which historically have been difficult to treat, still seem to be the population hardest to cure, as also reflected by our study results $[10,14,17]$. In the NEUTRINO trial, a phase 3 study in previously untreated patients with HCV genotype 1, a 12-week regimen of SOF plus RBV and peg-IFN-alfa-2a was administered. Total SVR 12 rates were $90 \%$ and SVR 12 rates for patients with cirrhosis were $80 \%$. [14]. In a further small study involving treatment-naive patients with HCV genotype 1 infection and a high prevalence of advanced fibrosis and cirrhosis, a 24-week regimen of SOF and RBV resulted in SVR rates of $68 \%[8,18]$. In our study population total SVR 12 rates were $74 \%$ and SVR 12 rates for patients with cirrhosis were $57 \%$. While overall virological response rates are encouraging, the relative high relapse rate in genotype 1 patients may

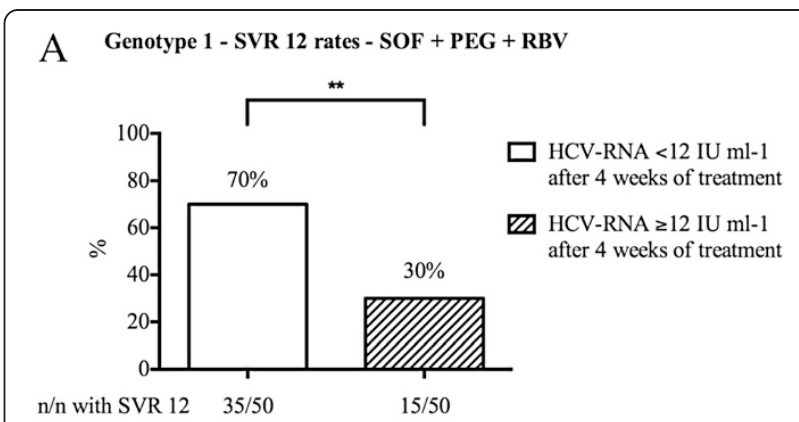

B Genotype $1-$ SVR 12 rates $-\mathrm{SOF}+\mathrm{RBV}$

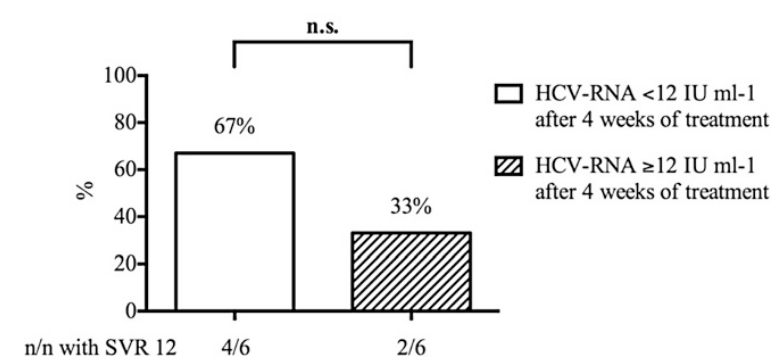

Fig. 3 Association of RVR for SVR 12 with regard to either IFNcontaining or IFN-free treatment regime. Association of sustained virological response rates after 12 weeks after the end of treatment (SVR 12) with RVR (level of HCV-RNA either < $12 \mathrm{IU}-\mathrm{ml}$ ) for patients with HCV genotype 1 infection receiving either SOF $+\mathrm{PEG}+\mathrm{RBV}$ (a) or SOF + RBV (b). $\mathrm{n}=$ number of patients. ${ }^{* *} p<0.0001$. n.s. $=$ non significant

suggest that dual DAA combinations should be favored at least for patients with negative predictors for a successful treatment outcome.

Surprisingly, total SVR 12 rates for patients with genotype 2 were lower than expected. In contrast to the results in our study population, the combination of SOF plus RBV has yielded very favorable results in previous studies $[9,14,19,20]$. In the FISSION trial, a phase 3 study involving previously untreated patients with $\mathrm{HCV}$ genotype 2 infection, a 12-week regimen of SOF and RBV showed total SVR 12 rates of $95 \%$ and SVR 12 rates of $83 \%$ for patients with cirrhosis [14]. In comparison, total SVR 12 rates for patients with genotype 2 in our collective was $79 \%$ and was only $50 \%$ regarding patients with cirrhosis.

Table 4 Change from baseline to SVR 12 in patients with HCV genotype 1 infection

\begin{tabular}{lccc}
\hline & Baseline & SVR 12 & p value \\
\hline Platelets (10E3 $\mu \mathrm{l}-1)$ & $171 \pm 81$ & $173 \pm 76$ & 0.8913 \\
Total bilirubin $(\mathrm{mg} \mathrm{dl}-1)$ & $1.2 \pm 1.0$ & $0.7 \pm 0.4$ & $\mathbf{0 . 0 0 5 2}$ \\
INR & $1.03 \pm 0.12$ & $1.06 \pm 0.21$ & 0.4964 \\
Creatinine (mg dl-1) & $0.77 \pm 0.18$ & $0.80 \pm 0.17$ & 0.5529 \\
\hline
\end{tabular}

Data are expressed as means \pm SD

SVR 12 sustained virological response at 12 weeks after end of treatment Boldface data statistically significant 
Table 5 Adverse events and hematologic abnormalities

\begin{tabular}{|c|c|c|c|}
\hline & $S O F+P E G+R B V$ & $\mathrm{SOF}+\mathrm{RBV}$ & $p$ value \\
\hline & total: 68 \% (81) & total: $32 \%(38)$ & \\
\hline \multicolumn{4}{|l|}{ Adverse events } \\
\hline Headache & $5 \%(4)$ & $5 \%(2)$ & 0.9515 \\
\hline Fatigue & $18 \%(14)$ & $16 \%(6)$ & 0.8170 \\
\hline Myalgia & $15 \%(12)$ & $11 \%(4)$ & 0.5072 \\
\hline Hashimoto's thyroiditis & $5 \%(4)$ & 0 & 0.1608 \\
\hline Decreased appetite & $3 \%(2)$ & 0 & 0.3256 \\
\hline Rash & $5 \%(4)$ & 0 & 0.1608 \\
\hline Thrush & $1 \%(1)$ & 0 & 0.4888 \\
\hline Hair loss & $10 \%(8)$ & 0 & 0.0435 \\
\hline Aggressiveness & $6 \%(5)$ & 0 & 0.1153 \\
\hline Pruritus & $5 \%(4)$ & 0 & 0.1608 \\
\hline Insomnia & $3 \%(2)$ & $3 \%(1)$ & 0.9662 \\
\hline Depression & $3 \%(2)$ & 0 & 0.3256 \\
\hline Acute psychosis & $1 \%(1)$ & 0 & 0.4888 \\
\hline \multicolumn{4}{|l|}{ Hematologic abnormalities } \\
\hline Anemia $(<10 \mathrm{~g}$ dl-1) & $75 \%(60)$ & $37 \%(14)$ & $<0.0001$ \\
\hline Leukocytopenia $(<3$ 10E3 $\mu \mathrm{l}-1)$ & $75 \%(60)$ & $16 \%(6)$ & $<0.0001$ \\
\hline Thrombocytopenia (<100 10E3 $\mu \mathrm{l}-1)$ & $60 \%(48)$ & $5 \%(2)$ & $<0.0001$ \\
\hline
\end{tabular}

Data are expressed as percent (number)

SOF sofosbuvir, PEG pegylated-interferon, RBV ribavirin

Boldface data statistically significant

Furthermore, in genotype 3 infected HCV patients, which have previously emerged as a particularly difficult to treat patient group, total SVR 12 rates in our study turned out to be higher than projected. The VALENCE trial yielded for previously treated and untreated patients with HCV genotype 3 infection total SVR 12 rates of 77$93 \%$ after a 24-week regime of SOF and RBV, while the subgroup of previously treated cirrhotic patients displayed only SVR 12 rates of $61 \%[9,14,16,19]$. With the addition of peg-IFN-alfa-2a to 12 weeks of SOF plus RBV in the LONESTAR-2 trial SVR 12 rates of $83 \%$ were achieved in this unfavorable subgroup of previously treated cirrhotics [20]. It can be speculated that these positive results may reflect a selection of patients with early stage cirrhosis with only minimally lowered thrombocyte counts, which were therefore regarded to be eligible to receive IFN. The patients in our collective showed total SVR 12 rates of $92 \%$ and even treatment-experienced cirrhotics showed a SVR 12 rate of $87 \%$ despite an interferon-free treatment regime in most of the cases. Eventually these data suggest that besides SOF plus RBV for 24 weeks, a SOF plus RBV and IFN treatment for 12 weeks should still be considered for IFN-eligible genotype 3 patients.

The NEUTRINO trial, a study of SOF plus RBV and peg-IFN-alfa-2a in previously untreated patients with
HCV genotype 4, presented total SVR 12 rates of $97 \%$ and for patients with cirrhosis of $50 \%$ [14]. Corresponding rates in our study population were 80 and $50 \%$.

However, it has to be noted that a comparison of the data of the aforementioned trials with the results of our study population is limited due to differences regarding the inclusion of treatment experienced patients and the treatment of patients with either one of two available treatment options and variable treatment duration.

Interestingly, besides the presence of cirrhosis, we observed that a level of HCV-RNA $\geq 12$ IU ml-1 by week 4 of treatment was a predictor for treatment failure in genotype 1 patients, despite the fact that early virological response appeared to be of limited value as a prognostic marker in previously published DAA-based studies [14, 20]. Regarding the subgroup of cirrhotics, SVR 12 rates were only $25 \%$ when HCV-RNA levels were $\geq 12$ IU ml-1 after 4 weeks of treatment. Notably, the predictive value of early virological response was only evident in genotype 1 patients receiving an IFN-containing regime, but not in patients on $\mathrm{SOF}+\mathrm{RBV}$. Taken into account that SOF + peg-IFN-alfa$2 \mathrm{a}+\mathrm{RBV}$ may still remain the standard of care in many regions of the world, because of the high costs of IFN-free treatment regimes, analysis of early virological response may be helpful to establish response-guided therapy regimes in the future. However, the sensitivity of HCV RNA 
quantification can differ between different tests. Patients who may have tested HCV RNA negative during antiviral therapy by older assays with a LLOQ of $\geq 50 \mathrm{IU} / \mathrm{ml}$ may test HCV RNA positive by highly sensitive HCV RNA assays. In our study the highly sensitive Abbott RealTime (ART) HCV assay (Abbott Molecular, Des Plaines, IL, USA) with the LLOQ of $12 \mathrm{IU} / \mathrm{ml}$ was used. Therefore, it might be reasonably assumed that different assays may have an influence on the predictive value of the early treatment response [21, 22].

Change in clinical chemistry from baseline to SVR 12 in patients with genotype $1 \mathrm{HCV}$ infection showed a statistically significant decline in total bilirubin. It might be speculated that the observed change in total bilirubin under successful HCV therapy in genotype 1 patients could be translated into an improvement of the MELD score of patients with advanced stages of liver cirrhosis and therefore treatment may lead to a delay or permanent prevention of liver transplantation.

As a limitation of the study, there is no data on the interleukin 28B haplotype of the patients in our cohort available. An association of viral clearance with this polymorphism was shown for antiviral treatment with peg-IFN-alfa and RBV, but not for SOF so far [23, 24].

In our patient cohort no data is available on baseline and post-treatment resistance-associated variants (RAVs) representing a further limitation of our study. However, SOF exhibits a high barrier to resistance and among patients who did not achieve SVR in recent trials, including the FISSION, POSITRON and VALENCE trials, SOF resistanceassociated variants (RAVs) were not detected $[9,14,19]$. On the other hand, the Q80K variant conferring resistance to the NS3 protease inhibitor simeprevir has been observed in $9-48 \%$ of untreated $\mathrm{HCV}$ genotype 1a-infected patients, leading to reduced SVR rates [25]. Although patients with baseline RAVs still exhibit high SVR rates, screening for variants conferring resistance may help to reduce treatment failures with respect to cost intensive treatment regimes.

Consistent with the safety profile of IFN, adverse events and laboratory abnormalities were more common in the SOF, RBV and peg-IFN-alfa-2a group. As seen in our study, adverse event profiles improve substantially in the absence of IFN. In view of the inconvenience and high rate of significant side effects of IFN, all-oral, IFNfree DAA therapies will become the first choice for treatment of patients with chronic HCV.

However, even though great strides have been made since the approval of the first DAAs in 2011, future research needs to address the current limitations in the antiviral efficacy of available therapies in the increasing number of patients with advanced liver disease and previous DAA treatment failure. With a growing number of patients who have failed under DAA-based therapy, there is still an emerging demand for further novel antiviral agents.

\section{Conclusion}

SOF-based therapy regimes are safe and lead to high rates of SVR 12. However, probably due to a large proportion of patients in our cohort with unfavorable conditions such as liver cirrhosis or pre-treatment failure or even the combination of both, the SVR rates of previous clinical trials were not attained in our patient cohort.

\section{Abbreviations}

DAA: Direct-acting antiviral; EASL: European association for the study of the liver: HCV: Hepatitis c virus; HIV: Human immunodeficiency virus; ITT: Intention-totreat; LLOQ: Lower limit of quantification; PEG: Pegylated-interferon; peg-IFNalfa-2a: Pegylated-interferon-alfa-2a; RAV: Resistance-associated variant; RBV: Ribavirin; RVR: Rapid virological response; SD: Standard deviation; SOF: Sofosbuvir; SVR: Sustained virological response.

\section{Competing interests}

NS received travel support from BMS and Gilead Sciences. MFS receives research funding from Gilead Sciences. TZ received lecturer, consultant fees and/or travel support from AbbVie, BMS, Boehringer Ingelheim, Gilead Sciences, Janssen Pharmaceuticals, MSD and Roche. JMS and MAW received lecturer and consultant fees from Gilead Sciences, Janssen Pharmaceuticals, AbbVie and BMS. PRG received consultant fees from Gilead Sciences, Janssen Pharmaceuticals, BMS and Roche. CE received lecturer fees and/or travel support from BMS, Gilead Sciences, Janssen Pharmaceuticals, MSD and Roche. KS received lecturer fees from Roche and Gilead. AP received travel support from AbbVie and BMS.

\section{Authors' contributions}

NS and AP drafted the original manuscript, contributed to the study design, performed the statistical analysis, interpreted the results and collected the data. CE contributed to the study design, interpreted the results, collected the data and critically revised the manuscript. MS, TZ, MW and TZ collected the data. WS and PG critically revised the manuscript. KS, CA and JS interpreted the results, collected the data and critically revised the manuscript. All authors read and approved the final manuscript.

\section{Acknowledgements}

We thank Thomas Bruckner for assistance in statistical analyses.

\section{Author details}

'Department of Internal Medicine IV, University Hospital Heidelberg, Heidelberg, Germany. ${ }^{2}$ Department of Internal Medicine I and Cirrhosis Center Mainz (CCM), University Medical Center Mainz, Mainz, Germany. ${ }^{3}$ Department of Internal Medicine II, University Hospital Mannheim, Mannheim, Germany. ${ }^{4}$ Department of Gastroenterology, Hepatology and Infectious Diseases, University Hospital of Magdeburg, Magdeburg, Germany.

Received: 14 April 2015 Accepted: 28 July 2015

Published online: 04 August 2015

\section{References}

1. Lavanchy D. The global burden of hepatitis C. Liver Int. 2009;29 Suppl 1:74-81.

2. Esteban JI, Sauleda S, Quer J. The changing epidemiology of hepatitis C virus infection in Europe. J Hepatol. 2008;48(1):148-62.

3. Davis GL, Albright JE, Cook SF, Rosenberg DM. Projecting future complications of chronic hepatitis $C$ in the United States. Liver Transpl. 2003;9(4):331-8

4. Verna EC, Brown Jr RS. Hepatitis C virus and liver transplantation. Clin Liver Dis. 2006;10(4):919-40.

5. El-Serag HB, Mason AC. Rising incidence of hepatocellular carcinoma in the United States. N Engl J Med. 1999;340(10):745-50.

6. Murakami E, Tolstykh T, Bao H, Niu C, Steuer HM, Bao D, et al. Mechanism of activation of PSI-7851 and its diastereoisomer PSI-7977. J Biol Chem. 2010;285(45):34337-47.

7. Lam AM, Murakami E, Espiritu C, Steuer HM, Niu C, Keilman M, et al. PSI-7851, a pronucleotide of beta-D-2'-deoxy-2'-fluoro-2'-C-methyluridine monophosphate, is a potent and pan-genotype inhibitor of hepatitis $C$ virus replication. Antimicrob Agents Chemother. 2010;54(8):3187-96. 
8. Gane EJ, Stedman CA, Hyland RH, Ding X, Svarovskaia E, Symonds WT, et al. Nucleotide polymerase inhibitor sofosbuvir plus ribavirin for hepatitis $C$. N Engl J Med. 2013;368(1):34-44.

9. Jacobson IM, Gordon SC, Kowdley KV, Yoshida EM, Rodriguez-Torres M, Sulkowski MS, et al. Sofosbuvir for hepatitis C genotype 2 or 3 in patients without treatment options. N Engl J Med. 2013;368(20):1867-77.

10. Kowdley KV, Lawitz E, Crespo I, Hassanein T, Davis MN, DeMicco M, et al. Sofosbuvir with pegylated interferon alfa-2a and ribavirin for treatment-naive patients with hepatitis C genotype-1 infection (ATOMIC): an open-label, randomised, multicentre phase 2 trial. Lancet. 2013;381(9883):2100-7.

11. Kramer JR, Kanwal F, Richardson P, Mei M, El-Serag HB. Gaps in the achievement of effectiveness of HCV treatment in national VA practice. J Hepatol. 2012;56(2):320-5.

12. Backus LI, Boothroyd DB, Phillips BR, Mole LA. Predictors of response of US veterans to treatment for the hepatitis C virus. Hepatology. 2007:46(1):37-47.

13. European Association for the Study of the Liver. EASL recommendations on treatment of hepatitis C 2014. J Hepatol. 2014;61(2):373-95.

14. Lawitz E, Mangia A, Wyles D, Rodriguez-Torres M, Hassanein T, Gordon SC, et al. Sofosbuvir for previously untreated chronic hepatitis $\mathrm{C}$ infection. $\mathrm{N}$ Engl J Med. 2013;368(20):1878-87.

15. Lange $C M$, Zeuzem S. Perspectives and challenges of interferon-free therapy for chronic hepatitis C. J Hepatol. 2013;58(3):583-92.

16. Lawitz E, Gane EJ. Sofosbuvir for previously untreated chronic hepatitis C infection. N Engl J Med. 2013;369(7):678-9.

17. Sulkowski MS, Naggie S, Lalezari J, Fessel WJ, Mounzer K, Shuhart M, et al. Sofosbuvir and ribavirin for hepatitis $C$ in patients with HIV coinfection. JAMA. 2014;312(4):353-61.

18. Osinusi A, Meissner EG, Lee YJ, Bon D, Heytens L, Nelson A, et al. Sofosbuvir and ribavirin for hepatitis $C$ genotype 1 in patients with unfavorable treatment characteristics: a randomized clinical trial. JAMA. 2013;310(8):804-11.

19. Zeuzem S, Dusheiko GM, Salupere R, Mangia A, Flisiak R, Hyland RH, et al. Sofosbuvir and ribavirin in HCV genotypes 2 and 3. N Engl J Med. 2014;370(21):1993-2001.

20. Lawitz E, Lalezari JP, Hassanein T, Kowdley KV, Poordad FF, Sheikh AM, et al. Sofosbuvir in combination with peginterferon alfa-2a and ribavirin for non-cirrhotic, treatment-naive patients with genotypes 1, 2, and 3 hepatitis C infection: a randomised, double-blind, phase 2 trial. Lancet Infect Dis. 2013;13(5):401-8.

21. Schonning K. Comparison of the QIAGEN artus HCV QS-RGQ test with the Roche COBAS Ampliprep/COBAS TaqMan HCV test v2.0 for the quantification of HCV-RNA in plasma samples. J Clin Virol. 2014;60(4):323-7.

22. Sarrazin C, Dierynck I, Cloherty G, Ghys A, Janssen K, Luo D, et al. An OPTIMIZE study retrospective analysis for management of telaprevir-treated hepatitis $\mathrm{C}$ virus (HCV)-infected patients by use of the Abbott RealTime HCV RNA assay. J Clin Microbiol. 2015;53(4):1264-9.

23. Ge D, Fellay J, Thompson AJ, Simon JS, Shianna KV, Urban TJ, et al. Genetic variation in IL28B predicts hepatitis C treatment-induced viral clearance. Nature. 2009;461(7262):399-401.

24. Suppiah V, Moldovan M, Ahlenstiel G, Berg T, Weltman M, Abate ML, et al. $\mathrm{LL} 28 \mathrm{~B}$ is associated with response to chronic hepatitis $\mathrm{C}$ interferon-alpha and ribavirin therapy. Nat Genet. 2009;41(10):1100-4.

25. Schneider MD, Sarrazin C. Antiviral therapy of hepatitis C in 2014: do we need resistance testing? Antiviral Res. 2014;105:64-71.

\section{Submit your next manuscript to BioMed Central and take full advantage of:}

- Convenient online submission

- Thorough peer review

- No space constraints or color figure charges

- Immediate publication on acceptance

- Inclusion in PubMed, CAS, Scopus and Google Scholar

- Research which is freely available for redistribution

Submit your manuscript at www.biomedcentral.com/submit 